DOI 10.37882/2223-2974.2021.02.08

\title{
НЕДОПУСК В ЖИЛЫЕ ПОМЕЩЕНИЯ КАК ПРЕПЯТСТВИЕ ДЛЯ ВЫПОЛНЕНИЯ РАБОТ ПО КАПИТАЛЬНОМУ РЕМОНТУ ОБЩЕГО ИМУЩЕСТВА В МНОГОКВАРТИРНЫХ ДОМАХ - ПРИЧИНЫ И ПОСЛЕДСТВИЯ
}

\section{NON-ADMISSION TO RESIDENTIAL PREMISES AS AN OBSTACLE TO THE PERFORMANCE OF WORK ON MAJOR REPAIRS OF COMMON PROPERTY IN APARTMENT BUILDINGS - CAUSES AND CONSEQUENCES}

\section{S. Kartavov}

Summary: The article deals with the problem of non-admission to residential premises when performing major repairs of the common property of the owners of premises in apartment buildings. The reasons for this problem and possible solutions are analyzed. The scope of work that may be hindered by this problem is given. The low efficiency of the judicial solution of the problem of non-admission to the premises is shown, the author offers his own way of solving it.

Keywords: apartment building, common property of the owners of premises, major repairs of intra-house engineering networks, a lawsuit for granting access to residential premises, a management organization, notification of upcoming major repairs.
K апитальный ремонт многоквартирных домов на территории Российской Федерации, который выполняется по новым правилам, введенным в действие в декабре 2012 года [1], на сегодняшний день уже преодолел основную массу препятствий организационного плана и вышел на свою проектную мощность.

Первые годы реализации новой системы капитального ремонта можно охарактеризовать как стадию ее становления. В эти годы она занималась решением преимущественно организационно-технических вопросов: в сжатые сроки требовалось сформировать адекватную нормативную правовую базу, значительную часть которой составляют региональные акты, создать в каждом субъекте Российской Федерации регионального оператора, сформировать и утвердить региональные программы капитального ремонта, рассчитать и утвердить величину минимального взноса на капитальный ремонт, построить систему сбора (аккумулирования) этих вносов, выстроить систему отбора подрядных организаций, готовых выполнять работы по капитальному ремонту.
Картавов Сергей Александрович

соискатель, Уральский институт управления филиал Российской академии народного хозяйства и государственной службы при Президенте Российской Федерации, г. Екатеринбург kartavovs@yandex.ru

Аннотация: В статье рассматривается проблема недопуска в жилые помещения при выполнении работ по капитальному ремонту общего имущества собственников помещений в многоквартирных домах. Анализируются причины данной проблемы и возможные варианты ее разрешения. Приведены объемы работ, выполнение которых может быть затруднено данной проблемой. Показана низкая эффективность судебного решения проблемы недопуска в помещения, автором предложен свой способ ее разрешения.

Ключевые слова: многоквартирный дом, общее имущество собственников помещений, капитальный ремонт внутридомовых инженерных сетей, судебный иск о предоставлении доступа в жилое помещение, управляющая организация, уведомление о предстоящих работах по капитальному ремонту.

Решение всех этих и некоторых иных организационных задач сопровождалось резким отрицанием собственниками помещений нового для них бремени несения дополнительных расходов в виде взносов на капитальный ремонт и их общим неприятием новой системы капитального ремонта, что имело место даже в составе депутатского корпуса Государственной Думы Федерального Собрания Российской Федерации, отдельными представителями которого вскоре было инициировано заявление в Конституционный Суд Российской Федерации о проверке конституционности ряда положений Жилищного кодекса Российской Федерации о капитальном ремонте [2]. Для разрешения всех этих вопросов объективно требовались усилия и время.

Сейчас новая система капитального ремонта не только доказала свою состоятельность, но и продемонстрировала свои результаты. По данным Государственной корпорации «Фонд содействия реформированию жилищно-коммунального хозяйства» по состоянию на 1 июля 2020 года в стране подверглось капитальному ре- 
монту 724455 многоквартирных домов, что составляет 2558,36 млн. Кв.М. На 2020 год по всей стране запланированы работы по капитальному ремонту в 59855 домах [3].

Тем не менее, на сегодняшний день еще существует ряд системных проблем в этой области, актуальных как для Российской Федерации в целом, так и для отдельно взятых ее регионов. Одной из таких проблем является отказ собственников помещений предоставить доступ в свои помещения для выполнения работ по капитальному ремонту общего имущества, в частности для восстановления и замены внутридомовых инженерных систем, которые проходят внутри жилых помещений (сети теплоснабжения, водоснабжения и водоотведения). Нежелание собственников пускать в свои квартиры представителей подрядных организаций для производства работ может быть оправдано некоторыми неудобствами, которые будут им причинены, - далеко не каждый собственник безболезненно перенесет нахождение в его квартире посторонних людей, которые меняют какие-то трубы и пачкают грязными сапогами белоснежный кафель в ванной комнате. С другой стороны, такое нежелание не поддается логике - заменяемые при капитальном ремонте трубы являются имуществом собственника соответствующего помещения (пусть даже на праве долевой собственности), собственник уплатил за эти работы свои деньги (взносы на капитальный ремонт), но далее препятствует их выполнению.

На практике эта проблема во всех регионах России решается примерно одинаково - путем подачи в суд искового заявления к собственнику соответствующей квартиры о понуждении его предоставить доступ. Суды общей юрисдикции в каждом регионе страны имеют такие иски.

Кроме того, с этой практикой соглашается и Минстрой России: «непредоставление доступа к общедомовому имуществу при необходимости проведения ремонтных работ является поводом для обращения в суд заказчиком работ по проведению капитального ремонта или подрядной организации с целью разрешения вопроса обеспечения доступа к инженерным системам в судебном порядке» [4].

Сама по себе подача иска в суд не вызывает затруднений, и как способ достижения успеха имеет право на существование. Однако, нам представляется, что к помощи суда необходимо прибегать лишь в крайнем случае - когда нарушенные права и законные интересы никто иной защитить и восстановить не может. Но для того, чтобы каждый раз прибегать к помощи суда для организации работ в масштабах страны и в тех объемах, которые запланированы региональными программами капитального ремонта, региональным операторам потребуется содержать армию юристов.
Анализ региональных программ капитального ремонта многоквартирных домов, утвержденных субъектами Российской Федерации, позволяет утверждать, что работы по капитальному ремонту инженерных сетей (за исключением сетей газоснабжения и электроснабжения) в совокупности составляют примерно одну треть от всех видов работ (21,2\% в Москве, 25,4\% в Республике Калмыкия, 33,2\% в Челябинской области, 35,5\% в Белгородской области, 36,8\% в Иркутской области) [5]. Здесь мы приводим статистику исключительно за 2020 год, которая, безусловно, меняется по годам в большую или меньшую сторону. Тем не менее, общая тенденция соотношения видов работ по капитальному ремонту в регионах постоянна, отдельные примеры резких скачков и падений являются скорее исключением, нежели правилом, и вызваны решениями региональных властей по отдельным видам работ - в качестве примера можно привести массовую замену лифтов в некоторых регионах, а также решение Минстроя России о государственной поддержке этих видов работ, что не могло не отразиться на общей статистике.

Таким образом, судьба примерно одной трети из всех запланированных в стране работ по капитальному ремонту многоквартирных домов зависит от двух обстоятельств: от настроения собственника и от судебного решения. При этом судьба всех иных видов работ по капитальному ремонту (фундамента, фасада, подвала, крыши, лифтового оборудования) от этих обстоятельств не зависит - для их выполнения мнение конкретных собственников не требуется, и даже если они были бы против, законодательство содержит достаточно эффективный механизм, чтобы это мнение игнорировать.

Судебный порядок обеспечения доступа в жилые помещения нельзя назвать таким же эффективным механизмом обеспечения выполнения работ по капитальному ремонту. Причины здесь как минимум две.

Первая причина уже была нами обозначена чуть выше - значительные материальные и организационные затраты региональных операторов по подготовке исковых заявлений, последующее сопровождение процессов и обжалование решений, принимая во внимание, что иск следует подать к каждому собственнику помещения. Чаще всего квартиры находятся в собственности нескольких лиц. Исходя из этого, нетрудно подсчитать количество ответчиков, по которым необходимо добиться судебного решения: среднестатистический пятиэтажный дом, имеющий пять подъездов, содержит 100 квартир, умножая на три, получаем 300 ответчиков. И это только один дом. Тот факт, что собственников можно объединить в качестве соответчиков в рамках одного иска не очень упрощает задачу. Кроме того, учитывая процессуальные сроки и необходимость дальнейшего обжалования в вышестоящих 
судах вынесенных первой инстанцией отказов, сроки выполнения работ, которые утверждены программами, соблюдаться не будут. Подрядная организация, заключившая контракт на выполнение соответствующих работ, также связана договорными сроками, и ожидать окончания судебных разбирательств за пределами этих сроков она не обязана.

Федеральный законодатель на случай отсутствия доступа в помещения для выполнения работ предусмотрел возможность переноса соответствующих работ на более поздний срок - пункт 4 части 4 статьи 168 Жилищного кодекса Российской Федерации [6].

Указанная мера, на наш взгляд, позволит привести в порядок статистику о результатах за отчетный год невыполненные по причине недопуска в помещения работы «перейдут» на следующий плановый период и уже не будут значиться как невыполненные. Однако, представляется маловероятным, что перенос работ на более поздний период сам по себе как-то поможет решить проблему с недопуском и повлиять на позицию собственников по данному вопросу. Так, если они были против в 2020 году, то более вероятно, что и в 2021 году они останутся при том же мнении.

В результате, как подрядчик, так и заказчик этих работ в следующем году должны будут заново пройти всю эту бюрократическую процедуру: собрать комиссию, выяснить мнение собственников, зафиксировать их отказы, перенести работы на следующий год.

Вторая причина, подтверждающая неэффективность судебного порядка обеспечения доступа в жилые помещения, заключается в отсутствии на сегодняшний день единообразной практики по принимаемым судами решениям в таких спорах. В результате даже подготовленное по всем правилам и поданное в суд исковое заявление не гарантирует того, что доступ в жилое помещение будет обеспечен.

Так, Нефтеюганский районный суд Ханты-Мансийского автономного округа - Югры 30.05.2019 отказал в удовлетворении иска регионального оператора (Югорского фонда капитального ремонта многоквартирных домов) к группе собственников помещений многоквартирного дома о предоставлении доступа к общему имуществу собственников помещений многоквартирного дома (инженерным сетям водоотведения, расположенным в жилом помещении) для выполнения работ по капитальному ремонту (дело № 2-1485/2019 М-1245/2019).

Спустя десять дней - 10.06.2019 - тот же Нефтеюганский районный суд (в другом составе) удовлетворил аналогичный иск Югорского фонда к другой группе собственников (дело № 2-1677/2019 М-1246/2019).
Данная ситуация является показательной даже не по причине вынесения судом противоречивых решений по идентичным спорам, а по причине принятия одним и тем же судом прямо противоположных решений по одному и тому же спору при абсолютно схожих условиях. Автор настоящей статьи счел возможным привести эту ситуацию в пример, поскольку он сам являлся автором вышеуказанных исков и непосредственным участником этих процессов (на стороне истца): идентичные иски (по тексту различались лишь составом ответчиков), идентичные дома, расположенные по соседству, идентичная техническая документация, один и тот же подрядчик, один и тот же договор подряда, один и тот же вид работ, одна и та же процедура уведомления собственников, вид работ установлен одним и тем же актом местной администрации, но решения суда разные.

В аналогичных многочисленных судебных спорах о предоставлении доступа в помещения суды также не придерживаются единообразной тактики в поиске оснований для отказа. Так, в качестве оснований для отказа, которые, по нашему мнению, нельзя признать обоснованными, суды указывают отсутствие надлежащего уведомления собственников о предстоящих видах работ, отсутствие доказательств того, что инженерные сети находятся в аварийном состоянии и требуют ремонта, отсутствие решения собственников о выполнении таких работ. Однако, если придать приведенным доводам силу правила, то в этом случае следовало бы признать за собственниками помещений право вообще заблокировать своими действиями любые работы по капитальному ремонту. Для этого достаточно лишь не принимать решения о капитальном ремонте.

Кроме того, порой даже наличие решений Верховного Суда Российской Федерации не является для нижестоящих судов достаточным указанием для принятия решения по вопросу о том, должен ли собственник предоставить доступ к общему имуществу, расположенному в его квартире, для выполнения капитального ремонта. Так, Судебная коллегия по гражданским делам Верховного Суда Российской Федерации своим определением от 07.05.2019 № 4-КГ19-6 буквально указала следующее, цитирую: «суд апелляционной инстанции сделал ошибочный вывод о том, что право требовать допуска в занимаемое потребителем помещение у представителей исполнителя имеется только тогда, когда такое требование обусловлено аварийной ситуацией или жалобами других потребителей на нарушение их законных прав. Как было указано выше, такое право имеется у представителей исполнителя в силу прямого указания в законе, не зависит от конкретных обстоятельств и установлено, в том числе, для профилактики и предупреждения аварийных ситуаций или возможных нарушений прав граждан в будущем.» [7]. 
Приведенная позиция Верховного Суда Российской Федерации в свое время не смогла повлиять на решение Судебной коллегии по гражданским делам Суда ХантыМансийского автономного округа - Югры, который своим апелляционным определением от 01.10.2019 оставил без удовлетворения апелляционную жалобу на вышеуказанное решение Нефтеюганского районного суда от 30.05.2019, обосновывая это отсутствием договорных отношений между собственниками и подрядной организацией, выполняющей работы по капитальному ремонту, а также отсутствием доказательств ненадлежащего (аварийного) состояния инженерных систем, подлежащих капитальному ремонту. Мы не беремся в рамках настоящей статьи комментировать данное судебное решение, поскольку степень обоснованности его аргументов и без того очевидна.

Результатом отказных решений судов являются переносы работ по капитальному ремонту инженерных сетей многоквартирных домов на более поздние сроки, увеличение степени их износа и повышение рисков аварийных ситуаций, со всеми вытекающими последствиями. Такая ситуация, безусловно, требует адекватного и, по возможности оперативного, решения.

Несмотря на то, что виды и сроки работ по капитальному ремонту подлежат официальному опубликованию, которое происходит задолго до того, как к ним приступает подрядная организация, объективно, мало кто из собственников помещений отслеживает эти вопросы на официальных сайтах органов государственной власти, где публикуются региональные программы капитального ремонта.

С другой стороны, зайти в каждую квартиру многоквартирного дома, в котором запланирован капитальный ремонт, с тем, чтобы уведомить собственников соответствующих помещений о предстоящих работах и согласовать с ними дату и время их присутствия в квартире региональный оператор, как заказчик данных работ, не обязан; делать это по собственной инициативе он также не будет, потому что это его расходы (и весьма значительные), которые необходимо обосновать с точки зрения законности. Кроме того, законом установлен иной порядок уведомления о предстоящем капитальном ремонте, который, к сожалению, также малоэффективен.

Тем не менее, на сегодняшний день существует законный и по нашему мнению достаточно эффективный механизм, позволяющий не только уведомить собственников о предстоящих в их многоквартирных домах ра- ботах, но также обеспечить возможность согласования с ними различных аспектов этих работ, причем сделать это заблаговременно.

Правила осуществления деятельности по управлению многоквартирными домами, утвержденные постановлением Правительства Российской Федерации от 15.05.2013 № 416 [8], обязывают управляющую организацию раскрывать путем размещения на постоянной основе информацию о предстоящих работах, проверках оборудования, восстановительных работах, иных мероприятиях, которые могут потребовать присутствия собственников помещений в многоквартирном доме (их пользователей или их представителей) в определенное время, с указанием времени проведения таких мероприятий. Эта информация подлежит размещению на досках объявлений, расположенных во всех подъездах многоквартирного дома или в пределах земельного участка, на котором расположен многоквартирный дом (пункт 31 Правил).

Таким образом, уведомления о предстоящих работах по капитальному ремонту, в том числе, которые требуют присутствия собственников помещений, должны быть заблаговременно размещены в каждом подъезде многоквартирного дома. Именно отсюда каждый собственник сможет узнать о запланированных в его доме работах и сроках их выполнения. Вполне возможно, что какая-то часть собственников, узнав из этой информации конкретные сроки производства работ, контактные телефоны заказчика и подрядчика, а также разъяснения о том, почему эти работы необходимо выполнить и к каким последствиям может привести их невыполнение, заранее сформируют свою позицию относительно предоставления доступа в квартиру, а также будут иметь возможность согласовать какие-то аспекты предстоящих работ, заранее выяснить интересующие их вопросы, скорректировать удобное для проведения этих работ время. Даже в случае принятия собственником отрицательного решения о допуске представителей подрядной организации в свою квартиру, это решение своевременно попадет в управляющую организацию и к заказчику этих работ.

Исполняется ли должным образом указанная обязанность организациями, занимающимися управлением многоквартирных домов, - вопрос скорее риторический. Во всяком случае, этот вопрос может быть обращен в адрес государственных органов, уполномоченных в области лицензирования деятельности по управлению многоквартирными домами.

\section{ЛИТЕРАТУРА}

1. Федеральный закон от 25.12.2012 № 271-Ф3 «0 внесении изменений в Жилищный кодекс Российской Федерации и отдельные законодательные акты 
Российской Федерации и признании утратившими силу отдельных положений законодательных актов Российской Федерации» // СЗ РФ, 2012 , № 53 (ч. 1), ст. 7596.

2. Постановление Конституционного Суда РФ от 12.04.2016 № 10-П «По делу о проверке конституционности положений части 1 статьи 169 , частей 4 и 7 статьи 170 и части 4 статьи 179 Жилищного кодекса Российской Федерации в связи с запросами групп депутатов Государственной Думы» // С3 РФ. 2016. № 16. Ст. 2285.

3. Сайт в сети Интернет по адресу https://www.reformagkh.ru (дата обращения 13.10.2020).

4. Письмо Минстроя России от 16.01.2019 № 794-А0/06 «0 предоставлении доступа к общедомовому имуществу при необходимости проведения ремонтных работ» // СПС «КонсультантПлюс».

5. Сайт в сети Интернет по адресу https://www.reformagkh.ru (дата обращения 13.10.2020). Раздел, содержащий ежемесячные и квартальные отчеты субъектов Российской Федерации согласно формам приказа Минстроя России от 25 августа 2017 года № 1156/пр «0 внесении изменений в приказ Минстроя России от 1 декабря 2016 года № 871/пр «0б утверждении форм мониторинга и отчетности реализации субъектами Российской Федерации региональных программ капитального ремонта общего имущества в многоквартирных домах и признании утратившими силу отдельных приказов Минстроя России».

6. Жилищный кодекс Российской Федерации от 29.12.2004 № 188-Ф3 (ред. от 29.07.2017) // СЗ РФ. 2005. № 1. СЗ РФ. 2017. № 31 (ч. I). Ст. 4806.

7. Определение Судебной коллегии по гражданским делам Верховного Суда Российской Федерации от 07.05.2019 N 4-КГ19-6 // СПС «КонсультантПлюс».

8. Постановление Правительства Российской Федерации от 15.05 .2013 № 416 «0 порядке осуществления деятельности по управлению многоквартирными домами» // С Р РФ. 2013. № 21. Ст. 2652.

(с Картавов Сергей Александрович (kartavovs@yandex.ru).

Журнал «Современная наука: актуальные проблемы теории и практики»

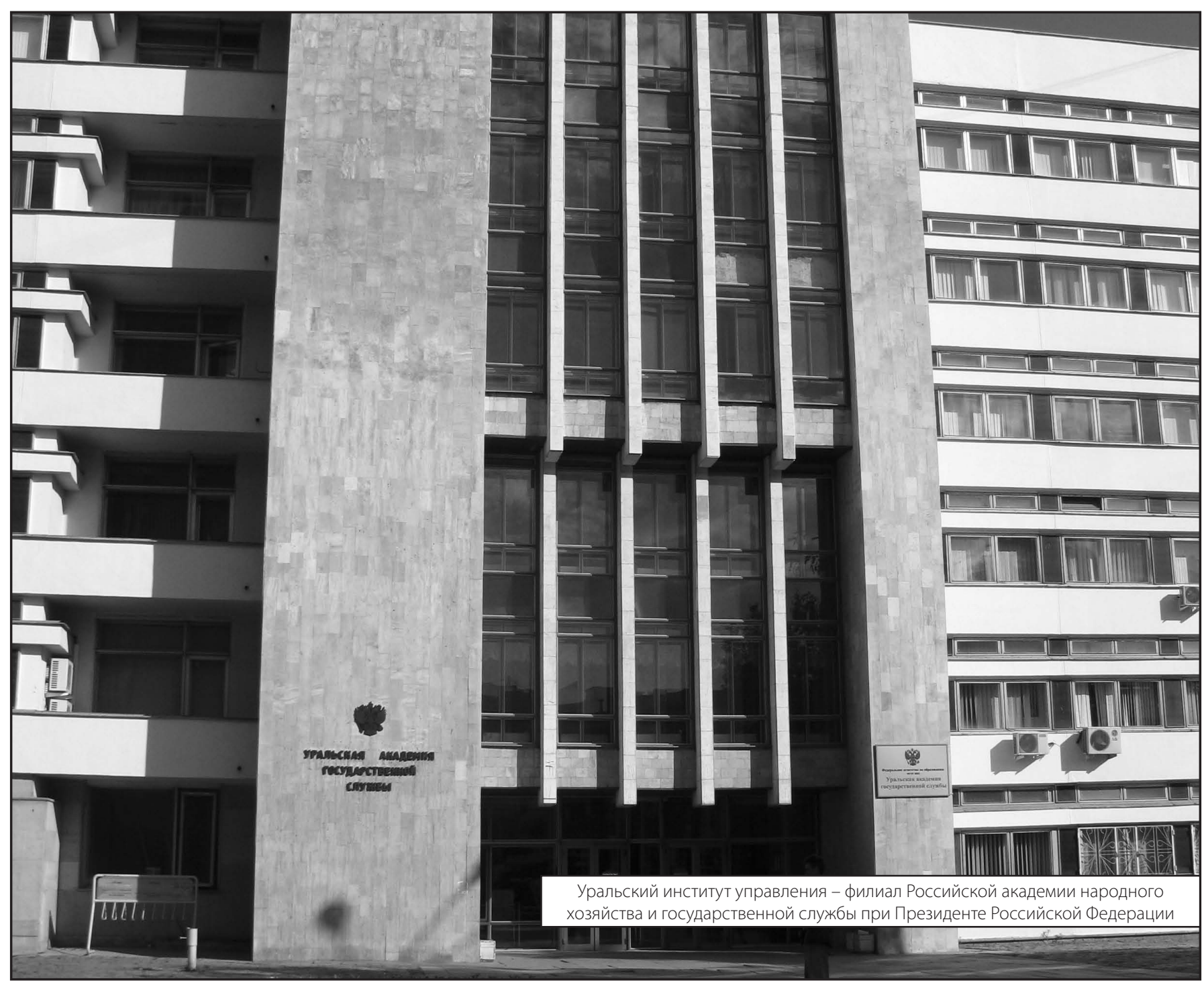

